\title{
Jueces electorales Y revolución digital ${ }^{1}$
}

\author{
Francisco Tortolero Cervantes ${ }^{2}$
}

\section{RESUMEN}

Los académicos de las democracias emergentes, como la mexicana, solíamos considerar a las democracias consolidadas como un paradigma que guiaba nuestras aspiraciones democráticas. Cada una de las innumerables reformas tenía que coincidir con las mejores prácticas internacionalmente reconocidas en materia electoral. Repentinamente, los modelos de comunicación política cambiaron con la proliferación de plataformas digitales (como Facebook y Twitter) que están suplantando a la prensa escrita, la radio y la televisión. La aparición de nuevas realidades propias de esta llamada revolución digital están aproximando estos dos viejos hemisferios entre sí. La conflictividad electoral que se vivió en los países latinoamericanos parece interesar cada vez más a las democracias que creíamos invulnerables. Es así como incluso en aquellos países, los jueces deben vivir su cotidianeidad con normas desfasadas con los tiempos que vivimos. Y los legisladores advierten que el tráfico de información en internet no se puede regular con las reglas de las libertades públicas tradicionales (como las de expresión y de prensa). La proliferación de campañas de desprestigio, conocidas también como fake news, está acercando a los países a encontrar soluciones que sobrepasen la falta de funcionalidad de las simples prohibiciones legales. En este artículo, se presentan algunos de estos desarrollos y puntos a considerar para abrir el debate y acercar a dos polos (viejas y nuevas democracias). Pero que ahora presentan realidades y controversias inéditas que, tarde o temprano, tendrán que llegar al conocimiento de los jueces electorales.

Palabras clave: Internet, ${ }_{i}$ Democratización ${ }_{i}$ Justicia electoral $_{i}$ Campañas electorales; Opinión pública.

1 Esta versión está adaptada y actualizada al formato de la revista. Fecha de recepción: 30 de septiembre de 2018. Fecha de aceptación: 9 de noviembre de 2018. Para citar el artículo: TORTOLERO CERVANTES, F. (2018). Jueces electorales y revolución digital, en Revista Con-Texto, n. ${ }^{\circ}$ 50, pp. 85-97. DOI: https://doi.org/10.18601/01236458.n50.06

2 Doctorado en Ciencia Política y Maestría en Instituciones por la Universidad de Paris I. Es miembro del Sistema Nacional de Investigadores nivel II es Licenciado en Derecho por la Facultad de Derecho de la UNAM. Actualmente, Investigador Titular "A", por oposición, en el Instituto de Investigaciones Jurídicas de la UnAm y Profesor de American Constitutional Law y de Federalismo en el Posgrado en Derecho de la misma Universidad. Fue asesor del Presidente de la Suprema Corte de Justicia de la Nación y Agente de Enlace con la Comisión de Venecia (hasta 2015).Correo-e: ftortolero@yahoo.com 


\section{ELECTORAL JUDGES AND DIGITAL REVOLUTION}

\section{ABSTRACT}

Scholars from developing democracies, such as Mexico, used to consider every consolidated democracy as a paradigm guiding our general expectations. Every new legal amendment would have to match the best practices, internationally recognized on electoral matters. Suddenly, political communication model completely changed since the expansion of digital platforms (such as Facebook or Twitter). Those platforms have being overlapping traditional media: Television, printing press, radio or TV. New realities produced by the current Digital Revolution seem to approach these old hemispheres betwen them. Electoral conflicts in Latin America seem more and more interesting to democracies considered to be invulnerable. Then, even in those countries, judges must live their day to day working after overlapped rules, overshoot by times we're living in. Legislators realize the internet traffic cannot be regulated through traditional rules related with public liberties (such as free press and expression). Proliferation of discredit campaigns, better known as fake news, are approaching countries to encounter legal solutions beyond simple prohibitions. In this paper, the author describes some of these developpements, appealing to some aspects opening debate in order to approach the aftermentioned two hemispheres dividing old and new democracies. Many of those controversies, able to be submitted sooner or later to electoral judges.

Keywords: Internet; ${ }_{i}$ Democracy, Electoral Courts ${ }_{i}$ Campaigns $_{i}$ Public Opinion.

La Cuarta Revolución Cognitiva que emana del tránsito a la Era digital está impactando en los resultados de las elecciones; incluso en las democracias que creíamos invulnerables. Los órganos del Estado que se ocupan de garantizar la legalidad electoral, empiezan a plantearse preguntas ante problemas que hoy, parecen no tener solución ${ }^{3}$. Con agentes del Estado que disponen de herramientas anacrónicas: reglas del siglo XIX para problemas del XXI.

Hasta hace poco tiempo, el mundo de las instituciones electorales parecía dividido en dos hemisferios. En el hemisferio de las democracias consolidadas, la normalización de las elecciones era tal, que nadie cuestionaba los resultados finales de los comicios, que se anunciaban normalizados al punto del pasmo; en Inglaterra, Alemania o Suiza sonaba cada vez más improbable tener que acudir a mecanismos arbitrales para resolver diferencias postelectorales. Los ciudadanos contaban los votos y los contaban bien. En aquel hemisferio, sonaba excesivo atribuir a tribunales de última instancia las funciones de contencioso electoral ${ }^{4}$.

3 Manucci, LucA "Populism and the Media", en Rovira, C. et al. (ed), The Oxford Handbook of Populism, Oxford University Press, 2017, pp. 467-487.

4 Sin embargo, es conocida la jurisprudencia administrativa francesa, que desde 1875 confiere al Conseil 
En el otro hemisferio, el de las democracias incipientes, como las latinoamericanas, asiáticas o africanas, el descrédito en las elecciones nunca dejó de encarnar uno de los principales retos de nuestras aspiraciones constitucionales. Asumiendo que un resultado aceptado por todos los contendientes inscribiría a cada país en la normalidad, las prioridades institucionales se fueron dirigiendo a confirmar triunfos incuestionables. Dejando para un segundo momento mejorar la calidad sustantiva de la democracia cotidiana ${ }^{5}$. Pero derivado de la misma revolución cognitiva, esta aparente división planetaria se empieza a diluir.

\section{REVOLUCIÓN DIGITAL Y ELECCIONES}

En las democracias que creíamos invulnerables, la normalización de la declaración de resultados volvía casi imperceptible la necesidad de establecer mecanismos administrativos o judiciales para resolver diferencias; y sin embargo, el brote esporádico de conflictos postelectorales confirmaba que tampoco se podía prescindir de mecanismos legales ${ }^{6}$ para generar confianza en los resultados.

Al final, se sabía que por más sobresaltos que ocurrieran en los países del primer hemisferio, la democracia seguía firme, en tanto funcionaban bajo el postulado del ejercicio responsable del poder, en el día a día. Los países del segundo hemisferio seguíamos luchando por la edificación de procesos electorales incuestionables, marcados por el Día "D": la jornada electoral, que ocurría cada dos, tres, cuatro, cinco o seis años.

En las primeras, no se aludía al fraude en las elecciones, pues desde que se universalizó el sufragio (desde fines del XIX, culminando a inicios del siglo XX), el electorado y la clase política confiaban en los resultados. Europeos y anglosajones veían en las democracias incipientes una espiral descendente a la que nunca habrían de caer. Hasta que vino el cambio en el modelo de comunicación política.

En prácticamente todos los países, sean ricos o pobres, se ha generado un cambio en la manera de hacer política ${ }^{7}$. Resultados electorales recientes hacen realidad el vaticinio expresado hace un cuarto de siglo, que borraba la institucionalización partidista y el antiguo clivaje entre izquierdas y derechas ${ }^{8}$.

Los partidos han sido sustituidos, desde sus militancias hasta sus plataformas, por individuos mediáticos y por movimientos que se anuncian espontáneos y sin ideología.

d'Etat la competencia (otrora compartida con el Parlamento) de calificar las elecciones (sobre todo, municipales y cantonales; más tarde las departamentales). Durante la primera década del siglo XX, se desarrollaron buena parte de los principios interpretativos en materia electoral. El advenimiento de la V República se marcaba un giro jurisdiccional, donde el Conseil Constitutionnel adquirió la competencia de juez de la elección presidencial (después de 2000, de las de referéndum).

5 Rosanvallon, Pierre, La Légitimité Démocratique: Impartialité, Reflexivité, Proximité, Paris, Seuil, 2009

6 Véase el principal ejemplo en la elección de George W. Bush en 2000, que solo pudo ser saldado por la intervención muy cuestionada Corte Suprema en Gore v. Bush

7 CASTELls, MANUEL, The raise of network society, Oxford, Blackwell Publishers, 1996,

8 Bobbio, Norberto, Derecha e izquierda, Madrid, Taurus, 2014. 
Si tan solo tomamos en cuenta el lapso entre 2016 y 2017, personajes como Beppe Gri1lo, Recep Tayip Erdogan, Nigel Farage, Viktor Orban, Beata Szydlo, Donald Trump, Emmanuel Macron o Carles Puigdemont nos hicieron borrar las antiguas coordenadas con las que entendíamos la legítima pugna por las decisiones políticas fundamentales.

La división de los dos hemisferios mencionados habría dejado de tener sentido; sobre todo por la forma en que las nuevas generaciones interactúan con sus representantes políticos $^{9}$. Y esto último se perfila como una constante que empieza a unir al norte con el sur, presentando una indudable influencia en todos los sistemas de calificación de elecciones para los próximos años.

\section{DEMOCRACIA Y REDES}

Las redes sociales transformaron para siempre el modelo de comunicación masiva (que distinguimos de la comunicación de proximidad, que en términos de campañas y elecciones planteaba una comunicación cara a cara, que repartía el juego político entre candidatos y electores). No solo porque durante la pasada década aparecieron nuevas plataformas e instrumentos informáticos, con vehículos tecnológicos y formatos (como Facebook y Twitter). Es cierto que cambiaron los vehículos, pero también cambió la carretera.

Igual que cuando hace más de un siglo, Thomas Alva Edison inventó la bombilla eléctrica (de la que podremos dibujar un símil con la computadora personal). Lo que parecía un invento aislado, fue secundado por la creación de plantas eléctricas (en nuestro símil, las redes de internet), capaces de dotar de electricidad a barrios enteros de las grandes ciudades.

La bombilla significó un cambio de era, aunque no por la invención en sí misma. La revolución vino cuando (casi de inmediato) se inventaron las centrales eléctricas urbanas. La transformación implicaba que un invento aislado podía llegar a más personas cuando se unía a una red eléctrica. Fue el funcionamiento en red lo que transformó la forma de concebir las ciudades. Igual ocurrió cuando internet se fue ubicando en el centro del juego democrático.

Al constatar que una computadora personal puede conectarse con todas las computadoras personales del mundo, la dimensión de la informática cambió nuestras vidas. Con invenciones distintas, pero bajo el mismo principio.

En el ámbito electoral, la transformación también se inició cuando las computadoras fueron accesibles a todos; en México contamos actualmente con 90 millones de teléfonos celulares activos (con una proporción creciente de aparatos con acceso a internet). Pero al igual que ocurrió en las democracias consolidadas, la vuelta de tuerca ocurrió cuando las redes sociales fueron sustituyendo a los medios tradicionales como la prensa escrita, la radio y la $\mathrm{TV}^{10}$. El cambio de era se produjo cuando las comunicaciones, otrora unidireccionales, se volvieron interactivas. Esto ya les está ocurriendo a las democracias 
incipientes, y no va a dejar de ocurrir en la medida buena parte del electorado hoy excluido de las redes, tendrá cada vez más incentivos para acceder a internet de forma permanente.

\section{NUEVAS VULNERABILIDADES}

Frente a las nuevas formas en que se compite electoralmente por los cargos públicos y por la toma de decisiones colectivas, se está generando un espejismo de interlocución directa entre el gobernante y sus gobernados; entre el candidato y sus potenciales electores. Es en este punto donde se generan nuevas vulnerabilidades: como si los dos antiguos hemisferios unieran sus debilidades, al no lograr adaptar sus principios y sus reglas ante una conflictividad que está produciendo salidas cada vez más inesperadas, ligadas al mundo virtual de la web.

Pero sin que los entes públicos cuenten con herramientas suficientes, pues las instituciones políticas siguen procesando soluciones a partir de las viejas libertades públicas. Estas últimas se encuentran hoy rebasadas, si se trata de probar la previsibilidad del sufragio, frente a amenazas cotidianas como la manipulación digital, las fake news, la extraterritorialidad del internet, y un cúmulo de etcéteras que leemos a diario en la prensa, y que dejaron de una vez por todas el plano de la ficción. Todo esto significa que cambiaron las cartas, el tablero, los jugadores, dejando intocados los arbitrajes y las reglas del juego.

Aunque se compita a partir de programas de gobierno sin objetivos claros, hoy un webmaster astuto (Casaleggio Associati o Breitbart News de Steve Bannon) puede volver competitivos a candidatos sin experiencia alguna en cargos políticos, a través de un simple blog. La fórmula ganadora de Beppe Grillo, pero también la de Donald Trump, constó de muy pocos pasos: con un mensaje pastoral de fe en el progreso, sus candidaturas lograron encarnar al mundo digital como agente moralizador de una política nacional completamente corrupta ${ }^{11}$. Lograron denunciar con vehemencia que la sociedad está excluyendo a las mayorías, y que se genera un esquema de "ustedes" contra "nosotros". Aunado a la comunidad digital, este mundo dividido estaba basado en una doble persuasión: una comunicativa y otra política. La primera, que crea la ilusión de absoluta libertad en las redes. La segunda, que crea la ilusión de decisión colectiva por las redes. Esta es la utopía digital de Gianroberto Casaleggio.

De forma semejante al fulgurante triunfo de Beppe Grillo en Italia, Steve Bannon convocó a un pequeño grupo de investigación con el que construyó una historia con elementos reales y ficticios, para atacar la piedra angular de los grupos en el poder norteamericano, generando suficientes contenidos para ser usados como dardos. El golpe final se gestó al ir escogiendo a grupos de electores afines para reproducir al infinito el descontento expresado.

La propaganda dirigida está funcionando cada vez más como un traje a la medida; de la forma como opera la publicidad de productos comerciales en internet. Con la

11 TronCOni, FILIPPO, Beppe Grillo's Five Star Movement: Organisation, Communication and Ideology, London, Routledge, 2016. 
dificultad adicional de la falta de fronteras en la web, y en plena ausencia de reglas claras y adaptadas a estas nuevas realidades. Muy pronto nos dimos cuenta de que es sumamente difícil regular internet, entre otras razones porque el medio digital no se puede fijar en el espacio.

\section{CÓMO PASAMOS A LA OPINIÓN DIGITAL}

Dentro del mercado electoral, las herramientas informáticas no son solo una carretera distinta para enviar mensajes tele-dirigidos. La meritocracia del partido y el trabajo burocrático como organización territorial pierden relevancia frente a la rapidez con la que hoy nos comunicamos. Una plataforma aparentemente gratuita, como Facebook o Twitter, es mucho más eficiente que cualquier otro de los medios de comunicación tradicionales $^{12}$. Y lo es no solo para transmitir información, propaganda o para hacer una encuesta de forma más ágil y certera. Lo es por la ilusión participativa que genera.

La opinión pública se ha transformado en opinión digital; en una voluntad que se expresa en red. Como ambiente de comunicación, esta red logra conjuntar 3 elementos que, por supuesto, no son nuevos. Pero que están reconfigurando la esfera pública: el sistema político, los órganos de información y el electorado ${ }^{13}$. Un proceso similar parecía existir cuando la opinión pública se gestaba a partir de la información contenida en los medios impresos.

Antes de la revolución digital, lo que columnistas y periodistas avezados intentaban era encarnar una especie de "pilotaje" del consenso"14. Mientras que en los regímenes autoritarios se lograba controlar la emisión de mensajes, en los democráticos, los medios se asumían libres; o al menos orientados por élites independientes al gobierno. Con opinión propia, ejerciendo la crítica periodística, los medios tradicionales de información explicaban; influían a la opinión colectiva al banalizar las situaciones políticas. Eran factores determinantes para resolver una crisis, sumando consensos a favor de ciertos actores, o incluso, revirtiendo el de otros. ¿Qué papel jugaba entonces el elector promedio? Desde luego, ejercer su derecho a votar; cambiar las orientaciones políticas a cada elección. ¿Y qué más, además de fungir como espectadores? Pues no mucho más.

Ahora, internet presenta al público la ilusión de influir en las decisiones colectivas más importantes, y de hacerlo sin intermediarios. Esa es la imagen ideal del papel revolucionario de la web.

12 Cuando arrancaron las campañas presidenciales en 2016, los tres principales periódicos impresos en Estados Unidos (USA Today, Wasbington Post y New York Times) apenas sobrepasaban los 5 millones de ejemplares circulando diariamente, mientras Twitter contaba con 67 millones de usuarios y Facebook con 232 millones de cuentas en los Estados Unidos.

13 Jenkins, Henry, Convergence Culture: Where Old and New Media Collide, New York University Press, 2006.

14 De acuerdo con la propuesta de DeUTSCH, KARL, Los nervios del gobierno: modelos de comunicación y control político, Buenos Aires, Paidós, 1971. 
En esta nueva realidad empieza a perder sentido la regulación del espacio de los hoy arcaicos medios masivos. Y la tendencia no hará más que reforzarse en la medida que toda persona en el mundo aspire a contar con este medio de comunicación e información.

La web se anuncia como un movimiento independiente al establisbment político e informativo. Donde nadie está en condiciones de controlar la información. Porque a diferencia de los medios tradicionales, nadie puede controlar internet. Lo anterior, ¿significa entonces que internet sea un espacio libre de todo condicionamiento?

En tanto sus movimientos surgen de forma espontánea, con la interacción de individuos sin ninguna coordinación entre sí, la web es impermeable a los condicionamientos de cualquier establisbment ${ }^{15}$. De ahí que la revolución digital no solo significa un cambio de herramientas para explicar la vida política. Implica también la modificación, de raíz, de la comunicación política. Los antiguos escopetazos (que detonaba la prensa tradicional) se convierten hoy en tiros de precisión. De ahí que en la era de internet, la comunicación no ha quedado a salvo de manipulaciones.

\section{MANIPULANDO EL BIG DATA}

Sin demasiada sofisticación tecnológica de por medio, cada candidato puede hacer uso de la información recabada, individuo por individuo, contratando lícitamente a Yahoo, Google, Facebook y tantas otras compañías (que se han encargado de reunir el historial de cada persona, desde que empezó a tener una computadora personal o un teléfono inteligente). Los bancos de datos que conforman el Big Data permiten personalizar el tipo de mensaje (dicho en lenguaje informático, un mensaje unido en metadatos) que coinciden con las preferencias de cada individuo; léase, de cada elector que forma un eslabón de la red ${ }^{16}$.

En la llamada Black Web se pueden contratar en línea servicios para dirigir campañas de desprestigio, incluso desde el extranjero. Ni siquiera es necesario pensar que el Kremlin quiera influir en las próximas elecciones para elegir a cualquier alcalde de una capital del mundo ${ }^{17}$. El Oxford Internet Institute ya había detectado verdaderos ejércitos de voluntarios reales y "bots" que se encargaron de difundir y redifundir mensajes de desprestigio en estas plataformas durante las presidenciales de 2016 en Estados Unidos ${ }^{18}$. Los nuevos vehículos han influido en sembrar la desconfianza en los partidos tradicionales para volver triunfadores a aspirantes sin estructuras partidistas sólidas. Hasta ahora, lo han logrado en Filipinas, India, Francia, los Países Bajos, por solo mostrar un abanico poco usual de países.

16 Schonberger, Viktor y Kenneth Cukier, Big Data: la revolución de los datos masivos, Madrid, Turner Noema, 2013.

17 Green, YoshuA, Devil's Bargain: Setve Bannon, Donald Trump and the Storming of the Presidency, New York, Penguin Press, 2017.

Véase el Oxford Computational Project, en http://comprop.oii.ox.ac.uk/ 
El otro extremo de la manipulación mediática estriba en los intentos de complacencia mutua. La web ha llegado al punto de filtrarnos mensajes que nos son ajenos (por no decir molestos) para presentarnos contenidos a la carta, que nos hacen sentir bien; que compartimos con personas con ideas semejantes a las nuestras. Así, terminamos convencidos de no equivocarnos jamás, porque nunca tenemos que convivir con alguien que piense distinto a mí. Partiendo de una presunción difícil de vencer: que si pudiera financiar o votar por algún candidato, lo haría a favor de quien defienda lo que yo pienso.

\section{LA WEB, ¿ENCARNA LA LIBERTAD ABSOLUTA?}

En esta nueva era, hemos llegado a creer que las ideas circulan libremente, y que una vez que una idea se viraliza genera la impresión de volverse verdadera.

Pero los flujos de opinión en redes no generan comunidades estables; son tan solo opiniones volátiles, que cambian de un momento a otro. Las potencialidades de la plataforma digital tienden a generar un tráfico artificial, de suerte que esas ideas no se crucen nunca con ideas contrarias, distintas ni críticas ${ }^{19}$. Y aunque las legislaciones del mundo apuntan a evitar excesos degradantes que son capaces de provocar las expresiones de odio frente a la libertad de expresión, aquella precaución solo podría controlar los medios tradicionales.

La posibilidad de evitar choques entre mensajes también ha llegado a los canales de radio y TV (que, aunque en declive, todavía tienen una parte del mercado de la comunicación política). Pues el efecto generado en la web a través de la manipulación de metadatos se reproduce indirectamente en los medios tradicionales; por comodidad: yo solo sintonizo el canal de tele o radio que expresa las ideas que me son afines.

El sistema de comunicación política nos hace creer que siempre tenemos la razón. Así que a pesar de facilitar la libre circulación de información como nunca en la historia, parece que Internet llegó para desmantelar la noción de crítica. Que, al menos desde la Ilustración, distinguió a las sociedades modernas ${ }^{20}$, que dejaban atrás la forma de pensar del Antiguo Régimen.

En el ambiente "en red", suele pensarse que la libertad sería absoluta, pues la información circularía sin restricciones. Pero la propia naturaleza de las compañías de internet (que adquiere tanta o más notoriedad y poder que los Estados mismos, en función de su capacidad de almacenamiento de datos, medido en terabytes), generaría en cambio un ambiente parecido al de un acuario ${ }^{21}$. Un ambiente artificial que, en realidad, se mueve en torno a intereses más o menos determinados. Un ambiente controlado, que simula ser gratuito, pero en el que debemos pagar, con una moneda que entregamos todos los días a cambio: nuestros datos.

19 Bronner, G., La démocratie des crédules, Paris, Presses Universitaires de France, 2013.

20 KOSELLECK, ReINHART, Crítica y crisis: un estudio sobre la patogénesis del mundo burgués, Madrid, Tecnos-UAM, $2007,288 \mathrm{p}$.

21 IppOLiTA, Nell'aquario di Facebook, Milano, Ledizioni, 2012. 
Para acceder, gratuitamente, a estos servicios, tenemos que entregarles a estas compañías nuestra identidad como consumidores virtuales ${ }^{22}$. Entonces, en este nuevo universo de circulación, aparentemente gratuita e incontrolada de datos, tendría que intervenir algún arbitraje.

\section{7. ¿Y LOS TRIBUNALES TENDRÁN QUE PRONUNCIARSE?}

La pregunta es ya inevitable. Y llegó para quedarse. Pero la solución dista de ser senci1la. Tampoco es una pregunta puntual, más bien, puede declinarse en múltiples tópicos; casi todos sin solución evidente (en caso de ser planteadas ante un tribunal). Y no solo en la determinación final de los resultados de una elección. Los excesos del internet se manifiestan en el día a día del ejercicio del gobierno.

Cada semana podemos advertir un nuevo escándalo mediático derivado de los espacios de impunidad de los que goza quien navega en Facebook o Twitter, y encuentra la vía de expresión más letal, económica y difícil de rastrear. Esas compañías de software están tomando ventaja de la erosión democrática de las normas de la competencia política, empezando por los países con un desarrollo importante de sus redes informáticas.

Si la respuesta es afirmativa, y los jueces electorales se ven llamados a intervenir, encontrarán una primera dificultad, de dimensiones considerables. Que las reglas del juego político envejecieron con una velocidad inaudita. Siguen siendo reglas vigentes, cuyo origen podríamos situar en la segunda posguerra.

Decíamos que estas reglas ofrecen instrumentos arcaicos, que no parecen impedir a Facebook, desde Irlanda, seguir manipulando, ya no digamos los resultados electorales, sino las formas de gobernar del día a día ${ }^{23}$. Los mensajes de campaña, luego los de gobierno, quedan completamente excluidos del control (accountability) y la transparencia que exige cualquier democracia sana.

Pero la necesidad de arbitrajes se extiende hacia otros derroteros: el efecto de los meta-datos también llegó a los partidos.

La sutileza de los meta-datos aparece porque ni siquiera se tiene que bombardear a cada votante con el nombre del candidato que se pretende impulsar. La estrategia se ha limitado a la sencilla tarea de hacer más claros los clivajes entre grupos. En acrecentar las diferencias entre clanes. Utilizando el lenguaje del odio; ridiculizando; disparando fake news por todos lados.

A veces, lo que podría destensar un hecho sancionable por el derecho, atizado por las redes sociales, podría ser la política. En mayo de 2017, se había anunciado una manifestación de supremacistas blancos en Charlotesville. La alcaldía emitió un bando de policía prohibiendo que la manifestación se hiciera en pleno centro (donde se encontraban estatuas de personajes sureños de la Guerra Civil); invitaban a los manifestantes a reunirse en un parque a unos kilómetros del centro. Pero el ambiente se encontraba 
crispado debido a que durante las semanas anteriores, había circulado en Facebook una campaña de odio tele-dirigida a miles de cuentas de los habitantes de ese estado de la Unión americana. Pero los supremacistas no estaban solos: empezaron a recibir respuesta en las redes de simpatizantes neo-nazis. El día de la manifestación, nadie atendió la prohibición de acudir al centro de la ciudad. Y se inició una trifulca entre los dos grupos extremistas. Los policías no actuaron, a pesar de que "se reportaron 19 lesionados e incluso una persona fallecida"24.

Las investigaciones arrojaron varias interrogantes. Los organizadores habían contratado (lícitamente) Facebook, gastando 100.000 USD para difundir mensajes de odio. Los policías alegaban que no intervinieron en los enfrentamientos porque el bando emitido asumía que en esa parte de la ciudad no habría manifestación alguna. Se reportaron graves afectaciones contra los manifestantes. No hubo responsables. Sin duda, el manejo político fue muy deficiente, falto de toda previsibilidad. Y a posteriori, la dificultad de juzgar con las herramientas jurídicas existentes conduce a otra pregunta inevitable.

\section{8. ¿SE PUEDE REGLAMENTAR INTERNET?}

En Estados Unidos, un primer intento por regular los contenidos de mensajes electorales transmitidos por internet fue plasmado desde 2002, en la ley McCain-Feingold campaign finance act, que exige a los candidatos validar aquellos contenidos que realmente expresaron. Con ese reconocimiento, se suponía que asumían cualquier responsabilidad sobre sus contenidos. Era imposible saber que cinco años después se crearía Facebook. Frente a esta herramienta, los contenidos de la ley citada toparon con un esquema diferente de entender la privacidad. Con o sin reconocimiento del mensaje, un candidato podría acusar falsamente a otro el día previo a la elección sin que pueda probarse si esa nota infamante redujo votos en la consulta final. Existen solo algunas propuestas (muy poco escuchadas por las empresas de internet) para obligar a que los candidatos conserven al menos un repositorio de todos los mensajes que se emitieron en las campañas ${ }^{25}$.

Semanas después de lo ocurrido en Charlotesville, Theresa May expresó ante el Parlamento británico su intención de promover una reforma para sancionar a las empresas de internet que difundieran contenidos antidemocráticos o terroristas. En respuesta, Max Hill, contralor anti-terrorista (designado por el gobierno) se opuso abiertamente a esta idea: "no veo en qué pueda ayudar que el Parlamento criminalice a las empresas tecnológicas que no hacen lo suficiente; cualquier informático entiende que una vez generada una información, de nada sirve cancelarla, pues esta puede ser retomada por

24 JACKOBS, BEN, "Man charged with murder after driving into anti-far-right protesters in Charlottesville", The Gardian, 13 de agosto 2017.

25 DANiEl KREISS; New York Times del 8 de septiembre; Turrow, Joseph et al., "Americans roundly reject tailored political advertising" Working Paper, University of Pennsylvania, 2012. 
otra fuente, incluso informal, y circular por la red. Se vuelve imposible suprimir esos contenidos de la web ${ }^{26}$.

Con un razonamiento semejante, que habría podido funcionar con las reglas de los medios tradicionales pero no con la circulación de datos en internet, el 30 de junio de 2017 el Bundestag alemán aprobó una ley que responsabiliza a los dirigentes de empresa de los contenidos de lenguajes de odio, antisemitas o xenófobos, que estuvieran circulando en algún momento. Con base en esta nueva ley, es responsabilidad de las empresas de internet retirar tales mensajes (con la ya señalada imposibilidad técnica que eso representa). De no observarlo, las multas se fijaron hasta 50 millones de euros. Desde luego, compañías como Facebook pueden resistir eso y más (solo en 2016, sus ganancias fueron de 27 billones de dólares).

El ministerio de Justicia alemán dispuso 50 funcionarios para dar cumplimiento a la mencionada ley ${ }^{27}$. Por su parte, Facebook contrataría 3.000 empleados adicionales a los 4.500 ya existentes para controlar contenidos antidemocráticos de su plataforma. Esto parece más una concesión de la empresa para evitar enfrentarse al Estado alemán que una estrategia que busque resultados efectivos. El verdadero problema radica en que, si el Estado tuviera que actuar en última instancia para controlar internet, el esquema tradicional de las instituciones tendría que considerar a los tribunales.

\section{9. ¿Y DÓNDE QUEDARON LOS JUECES?}

Los tribunales del mundo se están empezando a enfrentar a esta batería de preguntas, como vimos, con muy pocas herramientas útiles para unir las antiguas problemáticas electorales con la revolución digital. Las tendencias interpretativas distan de ser congruentes; al menos en sentencias recientes en Alemania, donde el Tribunal Constitucional evitó aplicar su vieja jurisprudencia de 1952 y 1956 sobre la disolución de partidos anti-sistema, esta vez a inicio de 2017. Haciendo una hábil interpretación, esquivó la espinosa cuestión de disolver el partido de extrema derecha National Demokraten Parteit, NPD ${ }^{28}$. Que, a diferencia de los partidos disueltos en los años 50, logró el tercer lugar en escaños en las pasadas elecciones de septiembre en ese mismo país, con 12,6\% de votos a su favor y 93 diputados en el Bundestag ${ }^{29}$. Ha ocurrido lo mismo que en todas las democracias europeas: los votantes que antes preferían opciones dentro de los partidos ortodoxos de izquierdas o derechas, se están pronunciando por opciones que suenan innovadoras, que con frecuencia esconden mensajes antisistema. No digamos solo del encontronazo británico con el Brexit (UKIP); sino resultados preocupantemente elevados en elecciones recientes, por ejemplo a favor del Front National (FN); del Partido por la Libertad y la Democracia de Holanda (VDD); del Partido de la Libertad de Austria (FPÖ); a favor 
de independentistas catalanes o vascos; y a favor de una lista extensa de movimientos separatistas en Europa ${ }^{30}$. ¿Qué pueden entonces hacer los tribunales y las instituciones políticas ante estas nuevas realidades? ¿Pretender que no pasa nada?

Para empezar a desentrañar esta complejidad, una lectura responsable nos lleva a darnos cuenta de que las instituciones políticas están actuando en medio de marcos normativos que no corresponden a la realidad. Y sin afán de modificarlos, también es cierto que los jueces e integrantes de órganos reguladores del juego democrático podrían seguir soñando que el flujo de información en internet se puede restringir, reglamentar o prohibir ${ }^{31}$.

Como cada cambio de época, no hay nada como volver a los principios elementales. Tal vez no hacen falta grandes cambios normativos. Tal vez sea momento de simplificar las reglas y de confiar en la política; pensar que los gobiernos puedan ocuparse de generar una nueva utilería de incentivos. De dotar al ciudadano de condiciones para que se genere civilidad, capaz de revertir la erosión de la autocrítica. A los jueces entonces les correspondería determinar cuáles son las buenas prácticas, los lineamientos y principios fundamentales que también se desprenden de la Constitución, de las leyes y los tratados, para lograr garantizar las condiciones que permiten resultados electorales apegadas a las normas de referencia, que mantengan el sentido de comunidad. Los parámetros para que la revolución digital no se salga de cauce existen y están en nuestra tradición política y constitucional; la institucionalidad; la fortaleza de la representación política sobre los intereses de individuos o corporaciones privadas; léase de criminalidad internacional o los intereses estratégicos de gobiernos extranjeros.

Como medida legislativa, la opción de prohibir, se vuelve la peor de todas en este mundo donde el vehículo es incontrolable ${ }^{32}$. Los tribunales que se pronuncian en materia de elecciones deben entender su neutralidad con reservas. Pues también podría inferirse que su papel, en términos de esta revolución digital, es el de un garante de las instituciones; a la manera de la citada jurisprudencia alemana de la democracia militante de la década de 1950. De agentes que no solo están en el sistema para ser aplicadores mecánicos de la ley, sino para actuar a favor de un modelo, que no puede ser más que el democrático ${ }^{33}$.

La desaparición de dos hemisferios de países se conjuga con la magnitud del reto de determinar qué tipo de arbitrajes se van a tener que producir en torno a la comunicación digital. En este punto, los países que se pensaban aventajados sobre las democracias

30 Rivero, ANGEL, et al. (eds), Geografía del Populismo: un viaje por el universo del populismo desde sus orígenes basta Trump, Madrid, Tecnos, 2017.

31 BALKIN, JACK M., "Digital speech and democratic culture: A theory of freedom of expression for the information society", New York University Law Review, vol. 79, n. ${ }^{\circ}$ 1, April 2004, pp. 1-56.

$32 \mathrm{Y}$, sin embargo, todo indica que otra legislación de tonos prohibitivos deberá ser elaborada por el gobierno francés de Edouard Philippe, cuando tenga que negociar hacia finales de 2018 la aprobación legislativa de un proyecto de ley anunciado durante el mensaje de año nuevo del presidente Emanuel Macron, quien planteó diseñar una nueva ley que engendrara una supuesta acotación a las Fake news, en Le Monde del 4 de enero de 2018.

33 Tortolero Cervantes, Francisco, La disolución de partidos anti-sistema, México, TEPJF, 2009, 55 p. 
incipientes deberán ser los primeros interesados en entablar un diálogo para determinar, en última instancia en sede judicial, cómo conducir esta revolución digital.

\section{REFERENCIAS}

"Facebook and democracy", New York Times del 12 de septiembre 2017.

BALKIN, JACK M., "Digital speech and democratic culture: A theory of freedom of expression for the information society", New York University Law Review, vol. 79, n. ${ }^{\circ}$ 1, April 2004, pp. 1-56. Bobbio, Norberto, Derecha e izquierda, Madrid, Taurus, 2014.

Bostrom, N., "Are you living in a computer simulation? Pbilosopbical Quarterly n. ${ }^{\circ}$ 53, 2003, pp. 243-255.

Bronner, G., La démocratie des crédules, Paris, Presses Universitaires de France, 2013.

CaStells, Manuel, Redes de indignación y esperanza, Madrid, Alianza Editorial, 2012.

CASTELLS, MANuEL, The raise of network society, Oxford, Blackwell Publishers, 1996,

Daniel KreISS, New York Times del 8 de septiembre; TURROW, JOSEPH et al., "Americans roundly reject tailored political advertising" Working Paper, University of Pennsylvania, 2012.

DeUTSCH, KARL, Los nervios del gobierno: modelos de comunicación y control político, Buenos Aires, Paidós, 1971.

Green, Yoshua, Devil's Bargain: Setve Bannon, Donald Trump and the Storming of the Presidency, New York, Penguin Press, 2017.

IPPOLITA, Nell'aquario di Facebook, Milano, Ledizioni, 2012.

Jenkins, Henry, Convergence Culture: Where Old and New Media Collide, New York University Press, 2006.

KOSELLECK, REINHART, Crítica y crisis: un estudio sobre la patogénesis del mundo burgués, Madrid, TecnosUAM, 2007, $288 \mathrm{p}$.

Le Figaro de 17 de enero de 2017

Le Monde de 3 de julio de 2017.

Le Monde del 4 de enero de 2018.

Libération del 25 de septiembre de 2017

ManucCI, LuCA, "Populism and the Media", en Rovira, C. et al. (ed), The Oxford Handbook of Populism, Oxford University Press, 2017, pp. 467-487.

MatTelart, ARmand, "Comment est né le mythe d'internet", Le Monde Diplomatique, agosto de 2000.

NeGroponte, NiCHOLAS, El mundo digital, Barcelona, Bailén, 1995.

Oxford Computational Project, en http://comprop.oii.ox.ac.uk/

Rivero, ANGEL, et al. (eds)., Geografía del Populismo: un viaje por el universo del populismo desde sus orígenes basta Trump, Madrid, Tecnos, 2017.

Rosanvallon, Pierre, La Légitimité Démocratique: Impartialité, Reflexivité, Proximité, Paris, Seuil, 2009.

SChOnberger, Viktor y Kenneth CuKIER, Big Data: la revolución de los datos masivos, Madrid, Turner

Noema, 2013.

Times del 3 de julio de 2017.

Tortolero Cervantes, Francisco, La disolución de partidos anti-sistema, México, TePJF, 2009, 55 p.

TrOnCONI, FILIPPO, Beppe Grillo's Five Star Movement: Organization, Communication and Ideology, London,

Routledge, 2016. 